\title{
Problems and Issues Related to Teaching Japanese to Students with Disabilities: Lessons Learned
}

\author{
Carlos L. Pimentel \\ Department of World Languages and Literatures, Western Michigan University, Kalamazoo, United States
}

\begin{abstract}
With increased advancement in assistive technologies, an increased number of students with disabilities are attending postsecondary institutions. This has resulted in more of these students taking foreign language courses either out of interest in the subject or in order to fulfill university or college requirements. While research has shown that some faculty members have received training in providing accommodations to these students, most feel inadequately equipped and unprepared to handle the teaching of such students. The present paper explores the problems and issues associated with teaching Japanese to college students at a large midwestern university with three different disabilities: PTSD, cerebral palsy, and complete visual impairment. The paper discusses problems facing each student as they learned Japanese, challenges for instructors, accommodations provided, and some solutions.
\end{abstract}

Index Terms - Japanese language pedagogy, disabilities, accommodations, universal design for learning

\section{INTRODUCTION}

In the United States, the Americans with Disabilities Act (ADA) of 1990, Section 504 of the Rehabilitation Act of 1973, and advances in assistive technologies (AT) have served to diversify the student population at American universities, and make postsecondary education more accessible to those with disabilities. According to the U.S. Department of Education, "colleges and universities are required to provide students with appropriate academic adjustments and auxiliary aids and services that are necessary to afford an individual with a disability an equal opportunity to participate in the school's program." Surveys by the National Center for Education Statistics (NCES) indicate that both in 2007-8 and 2011-12, $11 \%$ of undergraduates reported having at least one disability (U.S. Dept. of Ed.). Despite increasing numbers of students with disabilities enrolling in colleges and universities, a survey by Leyser, Vogel, Wyland and Brulle (1998) revealed that more than $40 \%$ of faculty felt they had limited knowledge of how to accommodate students, 55\% lacked familiarity of their institution's services and resources for students with disabilities, and $82 \%$ said they had limited or no training in addressing the needs of these students. According to West, Kregel, Getzel, Zhu, Ipsen and Martin (1993) a lack of understanding regarding accommodations, and how to implement them, can create obstacles for students with disabilities in colleges and universities. Lewis and Farrell (1999) point out that postsecondary institutions have provided some training for faculty, however there is still a lack of research regarding the specific problems and issues that students with disabilities have in specific disciplines of study. In particular, there is a paucity of research in the United States on the problems and issues associated with teaching foreign languages to students with disabilities. This paper will discuss problems, issues, and lessons learned related to teaching Japanese to students with three types of disabilities.

Recent research dealing with Japanese language instruction to students with disabilities involves case studies by researchers at Japanese universities whose students are exchange students from other countries. Kanayama's (2003) study describes the accommodations made, and the teaching materials used at International Christian University for the university's first visually impaired student enrolled in a summer language program. Kanayama and her colleagues used tape recordings, Japanese Braille, and screen reading software to teach the student the sounds of Japanese. Tanaka's (2006) study at Tsukuba University also describes the accommodations made for a visually impaired Japanese language learner attending an intermediate reading class. She states that the student requested that she be sent copies of the teaching materials by e-mail in advance, and that the instructors mention specific objects while teaching rather than using deictic pronouns such as kore ('this') and sore ('that'). The student also asked the instructors to "speak aloud anything they wrote on the blackboard." Nakagawa (2009) details the challenges associated with teaching elementary Japanese to a student with attention-deficit hyperactivity disorder (ADHD). A common challenge for the researchers and educators at these institutions has been the lack of knowledge of the incoming students' disabilities, thus leading to an inability to gather the resources necessary to provide the proper accommodations. These Japanese educators expect to follow the lead of the instructors in the students' home institutions with respect to how accommodations are handled, but more often than not, there is a lack of sharing of information that often leads to instructors having to extemporaneously modify lesson plans, instruction methods, learning assessments, and learning outcomes. Furthermore, 
in 2016 Japan began enforcement of the law known as Shōgaisha Sabetsu Kaishōhō (障害者差別解消法) banning discrimination against persons with disabilities and mandating that public and private institutions provide these individuals with reasonable accommodations. This has prompted Japanese institutions to look for further guidance from the institutions where their exchange students are coming from.

The following three sections of the paper report on the case studies of three students studying Japanese at a large university in the Midwestern United States. Each student has been studying Japanese for at least one year, and has expressed interest in studying on a yearlong exchange program in Japan. All of the students were registered with the campus Office of Disability Services for Students (DSS) and so instructors were aware of the accommodations for each student at the beginning of the semester. The course curriculum followed a communicative, student-centered pedagogical approach emphasizing the four skills of listening, speaking, reading and writing. The students were in a fifteen-week course that met four times per week for fifty minutes each. The average class size was twenty students. The typical student in the Japanese language program began their Japanese learning with no prior knowledge of the language before entering the university. This is the case for the three students that will be discussed. The instructors were a mix of experienced Japanese language professors and part-time instructional staff. The textbooks used were Banno, Ikeda, Ohno, Shinagawa and Tokashiki's Genki I ( $2^{\text {nd }}$ edition) (2011) and Genki II ( $2^{\text {nd }}$ edition) (2011). The case studies discuss the problems facing each student as they learned Japanese, the challenges for instructors, and the accommodations provided. The final section offers some solutions and unrealized benefits that a Universal Design for Learning (UDL) approach to teaching can offer to future students with similar disabilities.

\section{CASE Study 1: “JohN"}

John was a $2^{\text {nd }}$-year Japanese major, and Iraq and Afghanistan war veteran who suffers from Posttraumatic Stress Disorder (PTSD). His performance in his Japanese language classes was below average. His PTSD led to insomnia resulting in his inability to wake up in time to attend his Japanese classes. Furthermore, he suffers from anxiety and found it difficult to speak in Japanese in front of the other students. Many of the in-class activities focused heavily on speaking, and thus it became difficult for instructors to adequately assess his oral performance in the target language. In terms of accommodations, John was given double the amount of time to complete his exams, was allowed to tape lectures, and was allowed to take exams in a separate testing room at DSS. He was also allowed to miss up to 5 homework assignments per semester, and up to 5 class days without being penalized. ${ }^{1}$ When John came to class his PTSD made it such that he would have to sit close to the door, and he felt more comfortable when the door was open. Despite the door being behind him in the classroom, he often seemed distracted-periodically look over his shoulder toward it. The separate testing room allowed John to take the extra time needed to complete his exams, and it also made him he feel more at ease since he could take his exam with the door open. This also allowed the other students to take their exams in the classroom undisturbed from possible outside noise.

John's difficulty in communicating in Japanese in front of others made it difficult to adequately grade his spoken performance during in-class pair practice exercises, and during the times when he had to perform a dialogue with another student. The dialogue performances were $15 \%$ of the students' final grade, and so he was anxious about not being able to adequately perform them. Students were graded on a 1 to 5 scale based on their fluency, naturalness of pronunciation, and ability to memorize the dialogue.

John's biggest challenge was that he would appear visibly anxious and then freeze in the middle of the performance without continuing to the end. In the beginning of the semester the instructor thought that he might be freezing up because he had failed to fully memorize the dialogue. John insisted that he had memorized it but that his PTSD was the cause for his anxiety. The instructors then made another accommodation, and allowed him to perform the dialogues with them during scheduled office hours. In the instructor's office John seemed more at ease, he was able to completely perform the dialogues, and his grade subsequently improved.

\section{CASE Study 2: "SAMANThA"}

Samantha was a $3^{\text {rd }}$-year Japanese minor who has cerebral palsy and a speech impediment. As in the case of John, her performance in her Japanese language classes has been below average. Her cerebral palsy makes it difficult to process sounds, and she often needed to have phrases be repeated to her many times. The combination of her cerebral palsy and speech impediment made it difficult to assess her performance during speaking tests. During the tests she was usually presented with a context that would be used to elicit the most recent grammar and vocabulary that she learned. She often took more time than the other students to produce sentences. She was always given extra time to provide her oral responses, however, as with John, the instructors sometimes could not tell if she needed extra time because she had not full memorized the material, or because of her disability. This was especially the case since there were certain days when her performance was markedly better than others.

Samantha also had difficulty pronouncing Japanese words containing double consonant sounds such as kekkon ("marriage") and motto ("more"). When she did she would often stutter at the beginning of the word resulting in her

\footnotetext{
${ }^{1}$ As per the attendance and homework policies in the course syllabus, students were allowed to miss up to four days of class and up to four homework assignments without penalty.
} 
inability to fully pronounce the double consonant sound. Thus, kekkon and motto sounded like kekon and moto. In terms of auditory recognition she was able to recognize which words had double consonant sounds and which did not. This was confirmed when she was asked to write out words containing double consonants using the kana syllabary. Having realized this, her instructors then did not penalize her for making pronunciation errors such as these during the oral portion of her exams.

In speaking with her outside of class, she mentioned that she often looked at the mouths of her instructors and the other students to help her process the sounds of new vocabulary words. She then mentioned that it might be helpful if the instructors videotaped close-ups of their mouths while pronouncing new vocabulary words and phrases. The instructors agreed that this was a good idea and are currently making those videos. The series does not have a video component showing native speakers performing the dialogues in the texts, and so students must rely solely on in-class instruction and the audio files that accompany the textbook to acquire the sounds of Japanese.

\section{CASE STUdy 3: "XAVIER"}

Xavier is a $4^{\text {th }}$-year Japanese major who is congenitally blind, and began his study of Japanese language without any previous knowledge. His performance in his Japanese language classes has been on par with the top students in the class. $\mathrm{He}$ is also the first student that we had with a complete visual impairment. One of the initial problems facing instructors dealt with how to effectively plan lessons. Most of the instructors' lesson plans involved the heavy use of PowerPoint slides and photos to create contexts and situations designed to elicit previously learned Japanese. In order to convey the situations on the slides to Xavier, we had the other students explain what was on the slides in Japanese, or read the Japanese material on the blackboard. Instructors would also speak aloud any writing they did on the blackboard. Xavier was also given the materials that we would use in class ahead of time so that he could review them and prepare for each day's lesson.

Another problem that needed to be addressed was how to relay the textbook information to him. Xavier relies on the VoiceOver program in his Mac computer's operating system to read him materials in Japanese from websites, Microsoft Word files, and PDF files without pictures. Since Xavier was accustomed to using Word files to submit his assignments in other classes, we decided that this would be the best format for him to take quizzes, exams, and submit his homework assignments. He was able to obtain PDF copies of some of the textbooks, but not all, and in those cases the instructors had to copy the contents of the textbook into a Microsoft Word file so that the VoiceOver program could read it to him. This proved to be an extremely time consuming process that resulted in the hiring of a student-worker. The worker was a Japanese major who was in a more advance level than Xavier. He was paid to copy the text into a Word file, and also to describe any pictures that accompanied exercises in the textbook or workbook so that the context was clear enough for Xavier to successfully complete the exercises.

One example is from an exercise in Banno, Ikeda, Ohno, Shinagawa and Tokashiki's (2011) Genki II (2 $2^{\text {nd }}$ edition) the textbook that Xavier's class was using. The exercise shows a picture of two activities that a textbook character named Michiko is engaged in. It calls for the learners to describe them using the grammar point ながら (-nagara), which is used to describe two actions occurring simultaneously as in the sentence, "Michiko does X while doing Y." In the example picture, Michiko is seen watching television with a book open in front of her and a pencil in her hand so that it seems that she is also studying. The textbook shows sentences (1) and (2) below as being the two possible sentences used to describe the simultaneous actions in the picture.

1. terebi-o mi-nagara benkyoo shimasu
television-ACC watch-while study do ${ }^{2}$
'(Michiko) studies while watching television.'
2. benkyoo shi-nagara terebi-o mimasu
study do-while television-ACC watch

'(Michiko) watches television while studying.'

The example shows that when presented with a picture that is devoid of any other context either sentence is possible. However, the order of the activities both in English and in Japanese does affect how the activities rank compared to each other. Jorden and Noda (1990) explain that "while" in English differs from -nagara in Japanese in that the activity preceding -nagara is the subordinate activity, and the activity following -nagara is the primary activity, whereas in English, the activity preceding "while" is usually the primary activity, and the activity following "while" is the subordinate activity. The Genki II textbook does not mention this difference, and the Japanese instructors did not teach this difference to the students.

Hypothetically, this lack of explicit information could lead visually impaired students such as Xavier to acquire the order of the verbs in the -nagara construction in three ways. They could either: (i) consider the order to be interchangeable regardless of the way the picture descriptions were explained to them (i.e. as per the example given in sentences (1)-(2) above), (ii) show a tendency to mimic the order of the verbs in the picture descriptions given to them, or (iii) attribute a main and subordinate rank to the activities and produce sentences accordingly, regardless of the ordering of the picture description sentences.

${ }^{2}$ In this paper ACC and TOP stand for accusative case particle and topic particle respectively. 
Picture Description A: Michiko is shown brushing her teeth. There is a radio playing music in the background.

3. ha-o migaki-nagara ongaku-o kiiteimasu

teeth-ACC brush-while music-ACC is listening

'(Michiko) is listening to music while brushing her teeth.'

Picture Description B: Michiko is eating breakfast. She is also reading a newspaper.

4. asagohan-o tabe-nagara shinbun-o yondeimasu

breakfast-ACC eat-while newspaper-ACC is reading

'(Michiko) is reading a newspaper while eating breakfast.'

Picture Description C: Michiko is singing. She is also washing dishes.

5. uta-o utai-nagara osara-o aratteimasu

song-ACC sing-while dishes-ACC is washing

'(Michiko) is washing dishes while singing.'

Picture Description D: Michiko is watching a movie. She is also eating popcorn.

6. eiga-o mi-nagara poppukoon-o tabeteimasu

movie-ACC see-while popcorn-ACC is eating

'(Michiko) is watching a movie while eating popcorn.'

Sentences (3)-(6) are the Japanese sentences that Xavier produced based on the picture descriptions he was given. All of the sentences illustrate the equivalent pattern whereby the activity phrase preceding the -nagara clause corresponded with the first sentence listed in the picture description followed by the second activity phrase corresponding to the second sentence listed. In comparison, although all of the students were shown - through the textbook example giventhat grammatically, either order was possible, the sighted classmates showed a tendency to produce sentences consistent with a primary and subordinate rank attribution. For example, when asked by the author, most of the sighted students said they treated the teeth brushing in sentence (3), the breakfast eating in sentence (4), the dish washing in sentence (5), and the movie watching in sentence (6) to be the main activity with the other activities being the subordinate ones. Interestingly, the students who made these ranked the activities in this way, followed the English word order in their Japanese sentences whereby the main activity preceded the -nagara clause, and the subordinate activity followed it. When Xavier was asked for his rationale for producing the sentences that he did, he also mentioned attributing a primary and subordinate ranking to the activities, however, he admitted that he felt that he needed to follow the order of the activities as they were presented in the picture descriptions. After learning the difference between the order in English in Japanese, he was able to produce his own sentences reflective of the natural Japanese order.

The lessons learned here are that it took the examination of a blind student's work to realize two important things: (1) there was a lack of instruction with respect to the critical difference between English and Japanese "while" constructions that needed to be addressed, and (2) the way in which visual information (pictures) is translated into words can sometimes influence how visually impaired students acquire the target language.

Writing Chinese characters (kanji) in Japanese presents another set of challenges for visually impaired students. In order to write in kanji using Microsoft Word, one switches the keyboard language from Romanization to the hiragana syllabary and then after a particular word or words is typed, the spacebar is used to toggle through a selection of kanji that represent those word(s). The return key is then hit to select that appropriate kanji. In this way, sight is required to choose the correct Chinese characters that go along with a particular word, however, despite never having seen the characters, Xavier's writing is accurate over 90 percent of the time. This is because most of the words that he switches from hiragana to kanji can be found after clicking the spacebar only once. This is the pattern he has followed when writing in Japanese. At the elementary level of Japanese this posed little problem, however, his mistakes increased as he moved to higher levels. The following is the result of an inadvertent error that Xavier made when translating the sentence in (7a) from English to Japanese.

7a. The mother made her children go to church.

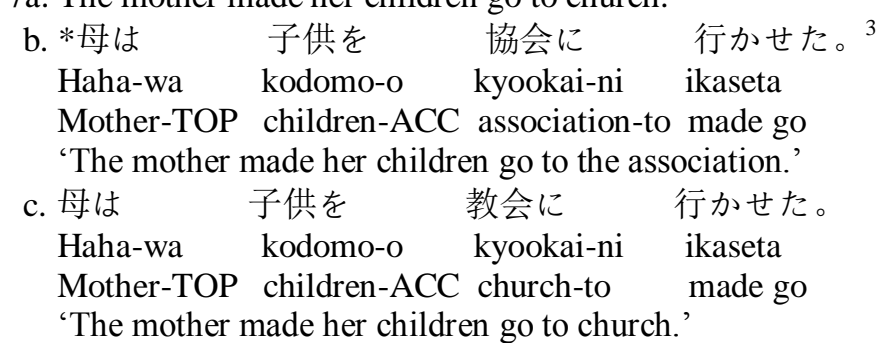

Sentence (7a) shows the sentence that was to be translated into Japanese, and (b) shows Xavier's incorrect response. Sentence (7c) shows the correct translation. The only difference between (7b) and (7c) is the kanji associated with the word kyookai; a homonym in the Japanese language. Therefore, Xavier input the hiragana correctly and afterward made the incorrect kanji selection, but was unaware of it since the word that was read to him by the VoiceOver software has a

\footnotetext{
${ }^{3}$ An asterisk (*) indicates that the sentence is ungrammatical.
} 
sound identical to that of the correct kanji variant. ${ }^{4}$ Another problem with the Microsoft Word Japanese input software for the visually impaired is that once a kanji selection is chosen - either correct or incorrect - that selection will then appear at the top of the list of choices from that point forward when the same hiragana word is again selected for conversion into kanji. Thus the probability of continuing to make the same error within the context of a single assignment or piece of writing increases for students who cannot see the text. Pimentel and Kondo (2015) point out that there is a software program called PC-Talker that reads out each kanji on the screen and provides more information about the meaning of each character allowing a visually impaired reader to distinguish between characters with the same pronunciation. However, it is designed for Japanese native speakers, and so the explanations of the different characters would be beyond the skill level of a Japanese learner at the intermediate level.

In terms of accommodations, Xavier was given extra time for his exams and in-class written assignments, was allowed to tape lectures, and was allowed to submit all of his work via a Microsoft Word document. Due to his inability to visually distinguish between the various Japanese homonyms and the particular kanji associated with each, he was never penalized for making such errors, however the following is an example of an error that he did make where he did not receive an accommodation. Xavier was tasked with translating the following sentence into Japanese: "I can travel alone." The translation that he gave is in (8a) below.

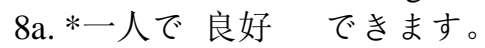

Hitori-de ryookoo dekimasu

Alone-by good can do

*'I can by myself good.'

b. 一人で旅行 できます。

Hitori-de ryokoo dekimasu

Alone-by travel can do

'I can travel by myself.'

Xavier's error was in his production of the word for "travel" in Japanese, which is ryokoo, however, he typed it into Microsoft Word as ryookoo. Since he added an extra vowel sound, the wrong kanji combination appeared thereby giving the wrong meaning. Afterward, when he was made aware of his error, he said that he had initially learned the sounds of the word incorrectly and thought that the word for 'travel' consisted of a long vowel sound in the first syllable of the word. Any time he has made such errors, he is immediately informed, and has done well to correct his mistakes.

\section{How a UNIVERSAL Design For LEARNing ApProach CAN HelP}

The case studies above describe the problems facing students with disabilities in the Japanese classroom and the countermeasures that were taken to ameliorate some of those problems. Most of these took the form of some kind of accommodation (e.g. extra time for testing, a relaxation of the attendance policy, allowing the use of MS Word file homework submissions, etc.). Therefore, changes to the courses policies were taken as a direct result of having students with disabilities in the classroom. However, creating courses with these students in mind from the beginning could provide benefits to all types of learners. Rose, Hasselbring, and Zabala (2005) describe the universal design approach as one where we, "create products and/or environments that are designed, from the outset, to accommodate individuals with a wider range of abilities and disabilities than can be accommodated by traditional applications. Rather than retrofitting ramps to existing buildings, the universal design movement in architecture educated architects in how to design buildings that are inherently accessible." The consequences of doing so inevitably end up benefiting a larger and more general population. For example, a building originally designed with ramps at the entrances and exits, serves to not only make the building more accessible to people with wheelchairs, but also makes it so for parents with strollers, people walking on crutches, and the elderly.

This idea of inherent accessibility is the foundation for designing courses and curricula with a Universal Design for Learning (UDL) approach in mind. When we design courses with all students - regardless of ability - in mind, from the outset, we make the material we are trying to convey more generally accessible. The case studies above show that UDL strategies, if implemented, could help disabled students and potentially benefit all students. Samantha was a student who wanted to view video close-ups of her instructors' mouths as they pronounced Japanese. Showing these videos to all students could foster a better understanding of the manner and place of articulation in the mouth that is involved when producing the sounds of Japanese. Furthermore, by having students describe pictures to Xavier, and having them read information to him in class, they are incidentally developing their speaking and reading skills in the target language. Moreover, in this case, since the receiver of the information is blind, the students have to make a conscious effort to explain the material accurately, in as much detail as possible. This allows instructors to continue the lesson in a studentcentered mode of teaching.

Implementation of these strategies has the even further benefit of making instructors aware of potential problems and deficits in our existing designs and teaching materials that might affect all of our students. In the case of Xavier, it was

\footnotetext{
${ }^{4}$ It should be mentioned that when switching the word kyookai from hiragana to kanji in Microsoft Word, the first kanji that can be selected is the one meaning 'church' (教会). The second that appears is the one meaning 'association' (協会) and thus Xavier must have inadvertently hit the space bar key twice when writing his sentence.
} 
description of the pictures in the textbook that led instructors to the realization that a crucial difference between Japanese and English was not addressed in the textbook. Xavier's responses in sentences (3)-(6) in section IV also serve to remind us that we must be constantly mindful of the manner in which we present information to our students. John's case teaches us that sometimes a change in setting might be necessary for our students to perform at their best.

\section{CONCLUSION}

In conclusion, this paper has looked at the problems associated with teaching Japanese to students with various disabilities. With the increased advancement of assistive technologies, an increased number of diverse students will be taking language classes out of interest or even to simply fulfill college and university requirements. Much more research in the fields of second language acquisition and applied linguistics must be done in order to help these students achieve their maximum potential in language classes. Finally, it is important not to forget that all students possess their own original motivations and reasons for taking our language courses. When planning courses and curricula, sometimes our perceptions of our students' limitations put us in danger of falsely assuming what those original motivations might be. As the author can attest, when Xavier was first taught Japanese, the assumption was that he would not be interested in learning about how Japanese and Chinese characters are written since he could not see them. This was actually far from the case. He mentioned to his instructors that learning Chinese and Japanese characters was a primary motivation for him to study Japanese language. Furthermore, he went on to take Chinese language courses, and participated in a Chinese calligraphy course. Learning to acknowledge disability while looking beyond it; this is a valuable lesson indeed.

\section{REFERENCES}

[1] Banno, E., Y. Ikeda, Y. Ohno, C. Shinagawa \& K. Tokashiki. (2011). Genki I: An integrated course in Japanese (2nd edn.). Tokyo: The Japan Times.

[2] Banno, E., Y. Ikeda, Y. Ohno, C. Shinagawa \& K. Tokashiki. (2011). Genki II: An integrated course in Japanese (2nd edn.). Tokyo: The Japan Times.

[3] Jorden, E.H., M. Noda. (1990). Japanese: The spoken language, part 3. New Haven, CT: Yale University Press.

[4] Kanayama, Y. (2003). Shikaku shogaisha no tame no nihongo kyōiku: Samā koosu ni okeru jugyo hokoku to kongo no kadai. ICU Nihongo Kyoiku Kenkyu 13, 109-119.

[5] Leyser, Y., S. Vogel, S. Wyland \& A. Brulle. (1998). Faculty attitudes and practices regarding students with disabilities: Two decades after implementation of Section 504. Journal of Postsecondary Education and Disability 13.3, 5-19.

[6] Lewis, L. \& E. Farris. (1999). An institutional perspective on students with disabilities in postsecondary education, National Center for Education Statistics, U.S. Department of Education, Statistical Analysis Report No. 1999-046.

[7] Nakagawa, Y. (2009). LD • ADHD Nihongo gakushusha e no shien ni kansuru ichikosatsu—-"Jissen nihongo" ni okeru kyoshi no jirei kara. Ibunka Komyunikeeshon Kenkyu 21,165-184.

[8] Pimentel, C.L. \& H. Kondo. (2015). Teaching Japanese to Students with Disabilities: Cross-campus Collaboration and Strategies for the Classroom. Proceedings of the $26^{\text {th }}$ Central Association of Teachers of Japanese Conference. University of Michigan, Ann Arbor. 105-112.

[9] Rose, D.H., T.S. Hasselbring, J. Zabala. (2005). Assistive technology and universal design for learning: Two sides of the same coin. In D. Edyburn \& R. Boone (eds.), Handbook of special education technology research and practice. Whitefish Bay, WI: Knowledge By Design, Inc., 507-518.

[10] Tanaka, A. (2006). Shikaku shogai o motsu nihongo gakushusha ni taisuru dokkai gakushu shien no kokoromi: Zenmo no ryugakusei ga juko shita chukyu nihongo dokkai jugyo no jissen hokoku. Tsukuba Daigaku Rryugakusei Sentaa Nihongo Kyoiku Ronshu 21, 63-75.

[11] U.S. Department of Education. (no date). Washington, DC. Questions and answers on disability discrimination under section 504 and Title II. http://www2.ed.gov/about/offices/list/ocr/frontpage/faq/disability.html (accessed 04/05/2017).

[12] West, M., et al. (1993). Beyond section 504: Satisfaction and empowerment of students with disabilities in higher education. Exceptional Children, 59, 456-467.

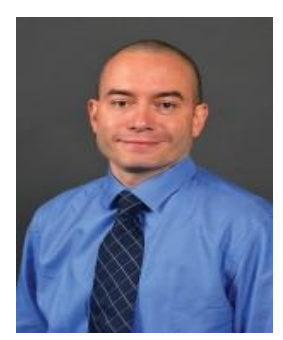

Carlos L. Pimentel was born in Brooklyn, New York. He received a B.A. in Japanese and linguistics from the University of Massachusetts-Amherst (1995), an M.A. in Japanese literature from the University of Massachusetts-Amherst (2006), and a Ph.D. in East Asian Languages and Literatures with specialization in Japanese linguistics from The Ohio State University (2014).

He served as the Director of the Japanese program at the University of Maryland for three years where he also taught Japanese language and linguistics. He is currently an Assistant Professor of Japanese language and linguistics at Western Michigan University in Kalamazoo. Prior to attending graduate school, he worked as an Assistant Language Teacher and Coordinator for International Relations for the Japanese government's Japan Exchange and Teaching (JET) Program in Kobe. He is the co-author of two articles: "Pronominal Interpretations in L2 Japanese" with Mineharu Nakayama, and "Teaching Japanese to Students with Disabilities: Cross-campus collaboration and Strategies for the Classroom" with Hikaru Kondo. His current research includes Japanese pronominal acquisition by native English speakers, Japanese language pedagogy, and applied linguistics.

Prof. Pimentel is a member of the Japanese Society for Linguistic Science, the American Association of Teachers of Japanese, the Central Association of Teachers of Japanese, the Japanese Teachers Association of Michigan, and the Linguistic Society of America. He also serves as a member of the national Japanese Language and Culture Advanced Placement (AP) Test Committee. 